\title{
The Effectiveness of Nursing Intervention Program on Emotional Distress, Self-Efficacy, and Liver Enzymes Among Hepatitis C Virus Patients Undergoing Antiviral Treatment Therapy (Sovaldi Medication)
}

\author{
Maaly. El. Malky ${ }^{1}$, Nahid. El Gahsh ${ }^{2}$, Merfat. M. Atia ${ }^{1}$ \\ ${ }^{1}$ Psychiatric Nursing Department, Faculty of Nursing, Shebin El-kom, Menoufia University, Egypt \\ ${ }^{2}$ Medical Surgical Nursing Department, Faculty of Nursing, Shebin El-kom, Menoufia University, Egypt \\ Email address: \\ maalyelmalky@yahoo.com (M. E. Malky),mervatatia@yahoo.com (M. M. Atia)
}

\section{To cite this article:}

Maaly. El. Malky, Nahid. El Gahsh, Merfat. M. Atia. The Effectiveness of Nursing Intervention Program on Emotional Distress, SelfEfficacy, and Liver Enzymes Among Hepatitis C Virus Patients Undergoing Antiviral Treatment Therapy (Sovaldi Medication). American Journal of Nursing Science. Vol. 5, No. 3, 2016, pp. 72-84. doi: 10.11648/j.ajns.20160503.12

Received: March 30, 2016; Accepted: April 19, 2016; Published: May 10, 2016

\begin{abstract}
Almost all patients receiving hepatitis $\mathrm{C}$ antiviral therapy will experience some treatment-related adverse effects. Emotional distress and fatigue can lead to early treatment discontinuation. Close monitoring is crucial throughout treatment. The nurses can promote adherence by counseling patients on the recognition and management of treatment- related adverse effects. The purpose of the study was to evaluate the effectiveness of nursing intervention program on emotional distress, selfefficacy and liver enzymes among hepatitis C Virus patients undergoing antiviral treatment therapy (Sovaldi medication). Quasi experimental design (one group pre/posttest) was used to achieve the aim of the study. The study was conducted in the Liver Institute at Shebin El kom District, Menoufia Governorate. A purposeful sample of 50 patients with hepatitis C virus patients undergoing antiviral treatment therapy (Sovaldi medication) from the above setting were recruited. Three instrument were used for data collection (1): Structured interview questionnaire to assess demographic and clinical data (2): Hospital anxiety and depression scale to measure emotional distress. (3): Self-efficacy scale to measure patients' self-efficacy. The result revealed that there were statistical significant improvements of patient's knowledge, patients' emotional distress, liver enzymes and self-efficacy post program than preprogram. Conclusion: Nursing intervention program is the key element for management of patients' emotional distress, self-efficacy and reduction of liver enzymes. Recommendation: psych educational program should be given for all patients with hepatitis $C$ virus undergoing antiviral treatment therapy to improve their knowledge about the drug and promote adherence by counseling patients on the recognition and management of treatment related adverse effect. Encourage them to discuss their problem with health care team and participate in self-help program to decrease emotional distress and increase self-efficacy.
\end{abstract}

Keywords: Emotional Distress, Self-Efficacy, Liver Enzymes, Nursing Intervention

\section{Introduction}

Hepatitis $\mathrm{C}$ virus (HCV) infection continues to be an important global health problem, and is one of the main causes of chronic liver disease worldwide. The long-term impact of Hepatitis C Virus infection is highly variable in Egypt, from minimal changes to extensive fibrosis and cirrhosis with or without hepatocellular carcinoma [1]. The World Health Organization (WHO) estimates that about 3\% of the world's population has been infected with $\mathrm{HCV}$, but most of them are unaware of their infection and more than 170 million chronic carriers who are at risk of developing liver cirrhosis and/or liver cancer [2]. Because of the world wide prevalence of hepatitis $\mathrm{C}$ virus and the associated cirrhosis and mortality, treatment is an important issue which may be carried out by combination therapy of Interferon and 
Ribavirin. But the adverse effects with this combination therapy are not rare. These effects could be managed effectively which has a great impact on patient compliance during the course of treatment. While new antiviral treatments for $\mathrm{HCV}$ are currently being investigated, these new agents will be used to enhance the treatment response rate and will maintain IFN and ribavirin as the core of the antiviral treatment regimen [3]. Therefore, in all likelihood, the neuropsychiatric symptoms that accompany HCV treatment currently will remain problematic with the emergence of the next generation of antiviral medications for the treatment of $\mathrm{HCV}$.

Hepatitis $\mathrm{C}$ is a chronic infection that causes psychic distress due to stigma, anxiety, and symptoms like excessive fatigue, it can reduce the patients' quality of life, and that can lead to depression. The changes in cytokine levels appear to decrease serotonin (5-HT) neurotransmission that may be involved in depression induced by IFN therapy [4]. Symptoms such as depression and fatigue are common in $\mathrm{CHC}$ and may have a profound effect on patient well-being. Furthermore, the treatment for $\mathrm{CHC}$ may aggravate these symptoms and lead to further HRQL (Health-Related Quality of Life) impairment [5]. Individuals infected with HCV experience psychological and somatic problems and report poor health-related quality of life. During HCV treatment, patients experience exacerbation of symptoms, treatment side effects, and poorer quality of life, making it difficult to complete treatment [6]. Also, reference [7] "stated that treatment of chronic HCV infection may temporarily worsen HRQoL, and common adverse effects of currently available agents include fatigue, muscle aches, depression and cognitive deficits".

Depression is one of the most common side effects of $\mathrm{HCV}$ therapy. Depression may range from mild to severe. In trials, $1 \%$ to $2 \%$ of patients reported suicidal thoughts or attempts, and $2 \%$ stopped treatment prematurely due to depression. About 1 in 3 people taking Sovaldi medicine will have depression as a side effect [8]. Depression will usually go away in 1 to 2 weeks after the treatment is over. Symptoms of depression may include: changes in appetite, decreased interest in sex or ability to perform, Feeling like life isn't worth living, Feeling restless, Feeling sad or moody most of the time, Feeling worthless or guilty, Irritability, Loss of energy or feeling slowed down, Loss of interest in things he likes to do, Problems concentrating, Problems remember and Trouble sleeping or sleeping too much [8]. Anxiety accompanies depression in close to half of all depressed patients. Sometimes referred to as agitated depression, such patients may have feelings of irritability, anger, restlessness, or being "on edge." Some people may report an increase in worrying or patients commonly report decreased interest in sex during HCV treatment [9].

The management of HCV treatment side effects has been almost exclusively under the purview of medical intervention, which is appropriate for the management of laboratory abnormalities or other medically severe adverse side effects. However, many treatment discontinuations and dose reductions may be due more to patients' inability to tolerate symptoms that interfere with life functioning [6]. Antidepressant medications have been the most readily available therapeutic option for HCV specialists to manage their patients' emotional distress. However, the evidence demonstrating the efficacy of antidepressants in ameliorating IFN-induced depression is equivocal [10] and [11]. Pharmacotherapy also has limitations (e.g., patient reluctance due to side effects, addiction history, and liver toxicity) and does not build self-efficacy or coping skills to empower patients to self-manage symptoms [6].

The nurse should assess patients who suffering from significant discomforts either related to disease symptoms or treatment side effects and take immediate action to help them manage it and encourage them to discuss their problem with health care team who can prescribe medications and offer other suggestions that are effective in managing such problems. These therapeutic measures improve liver enzymes, so nurse should monitor them from time to time to evaluate response, and support patient's adherence to therapy [12].

\section{Significance of the Problems}

Egypt has higher rates of hepatitis $\mathrm{C}$ virus than neighboring countries as well as other countries in the world with comparable socioeconomic conditions and hygienic standards for invasive medical, dental or paramedical procedures [13]. The prevalence of hepatitis C in Egypt is $14.7 \%$ of global prevalence. The drivers of hepatitis $\mathrm{C}$ virus epidemic in Egypt are not well understood, but the mass parenteral anti schistosomal therapy campaigns in the second half of the 20th century are believed to be the determinant of the high prevalence [14].Treatment is recommended for those who are proven $\mathrm{HCV}$ infection and signs of liver inflammation. Treatment for many years consists of a combination of pegylated Interferon alpha and antiviral drug such as Ribavirin for a period of 24 or 48 weeks, depending on HCV genotype. This produces cure rates between $45 \%$ and $80 \%$ [15]. Adverse effects of this treatment regimen are common, with half of people getting flu like symptoms and a third experiencing emotional problem [9].

Sofosbuvir (Sovaldi) is a newly nucleotide analog medication used in combination with other drugs for the treatment of hepatitis $\mathrm{C}$ virus (HCV) infection. Compared to previous treatment Sofosbuvir based regimens provide a higher cure rate and fewer side effects. Sofosbuvir is combined with other drugs such as ribavirin and lor Interferon in clinical safety trials, only the adverse effects of these combinations have been evaluated. Sovaldi is always taken with other medicines. It will not work on its own. It is commonly taken with either, Ribavirin, or Peginterferon alfa and ribavirin [16]. The treatment for chronic hepatitis $\mathrm{C}$ (CHC) is a combination therapy with Sovaldi and Ribavirin associated with many unpleasant side effects which are psychological in nature [17]. 
The most common side effects with Sovaldi in combination with Ribavirin and peginterferon alfa were similar to those commonly reported with Ribavirin or peginterferon alfa and included fatigue (tiredness), headache, nausea (feeling sick) and insomnia [18]. Common side effects of Sovaldi are changes in patients' mood, feeling depressed, feeling anxious and feeling agitated, blurred vision, severe headaches (migraine), memory loss, loss of concentration, weight loss, shortness of breath when exercising, stomach discomfort, constipation, dry mouth, indigestion, acid reflux, hair loss and thinning hair, dry skin, back pain, muscle spasms, chest pain, feeling weak, and getting a cold (nasopharyngitis) [14] and [19].

People with $\mathrm{CHC}$ on combination therapy will go through phases of depression, anger, frustration and despair as a result of the symptoms of $\mathrm{CHC}$ and side-effects of therapy [7] for these reasons many patients refuse to start treatment, probably due to concerns about adverse effects. [20] Mentioned that; "there is an opportunity for nurse practitioners with advanced skills to provide skillful management and education of patients with CHC. They can assist patients in managing their symptoms and if well managed, can influence patient compliance with treatment and enhance their chance of eradicating the HCV infection". Also, [22], mentioned that; "Clinical, hematologic, and neuropsychiatric adverse events have the potential of affecting the life quality of patients receiving this therapy; therefore, they need to be well understood by the prescribing physician and clearly explained to the patient before the onset of treatment". So the aim of the study is to determine the effectiveness of the nursing intervention program on emotional distress, self-efficacy, and liver enzymes among patients with hepatitis $\mathrm{C}$ virus undergoing antiviral treatment therapy (Sovaldi) medication. Emotional distress operationally defined as the obtained score of anxiety and depression measured by Hospital anxiety and depression scale: Developed by [23] before and after the nursing intervention program. Self efficacy operationally defined as the obtained score of self-efficacy measured by Self-efficacy scale: Developed by [24] before and after the nursing intervention program.

\section{Methodology}

\subsection{The Purpose of the Study}

The purpose of the study was to evaluate the effectiveness of nursing intervention program on emotional distress, selfefficacy, and liver enzymes among patients with hepatitis $\mathrm{C}$ virus undergoing antiviral treatment therapy (Sovaldi medication).

\subsection{Research Hypothesis}

The nursing intervention program will improve emotional distress (anxiety and depression), self-efficacy and liver enzyme than before the nursing intervention program.

\subsection{Research Design}

Quasi experimental design (one group pre/post test) was used to achieve the purpose of the study.

\subsection{Research Setting}

The study was conducted in the Liver Institute at Shebin El kom District, Menoufia Governorate.

\subsection{Subjects}

A purposeful sample of 50 patients with hepatitis $C$ virus undergoing antiviral treatment therapy Sovaldi medication), in the Liver Institute at Shebin El kom District who fulfils the following inclusion and exclusion criteria:

\subsubsection{Inclusion Criteria}

- Adult conscious patient, have a confirmed diagnosis of hepatitis C, age (from 18 to 60) years old.

- Patients who are treated with daily $\mathrm{SOF}+\mathrm{RBV}+$ weekly peg-INF for 12 weeks.

\subsubsection{Exclusion Criteria}

- Free from history of other physical or mental illness.

\subsection{Instruments of the Study}

Three instruments were used on this study:

Instrument (1):- Structured interview questionnaire sheet was developed by the researcher based on pertinent literature and guidance of expertise including three parts:-

Part one: to assess socio demographic data as age, sex, marital status, income and education.

Part two: to assess patient's clinical characteristics, such as past and present medical history, patients complains and results of liver enzymes.

Part three: to assess patient's knowledge about his disease and the medication prescribed.

Instrument (2):- Hospital anxiety and depression scale:This scale was developed and tested for its validity and reliability by [23] to measure anxiety and depression. It consists of 14 items in the form of four point Likart scale ranged from 0 to 4 point. Seven items for measure depression and the other seven items for measure anxiety. This scale was translated into Arabic and tested its content validity and reliability by the researcher. The scoring system for both anxiety and depression are as the following.

From 0-7 was normal.

From 8-11 was mild.

From12-17 was moderate.

From 18-21 was severe.

Instrument (3): Self efficacy scale: This scale was developed by [24] to measure self-efficacy of chronic ill patients. It was translated into Arabic and tested for its content validity and reliability by the researcher and it consists of 21 items in the form of likart scale, at point ranged from (1) to (10) (not at all confident take score (1) to totally confident take score (10). This scale divided into 3 items related to confidence in doing regular exercises, one 
item related to confidence on getting information about disease, 4 items related to confidence about obtaining help from community and friends, 3 items related to confidence on communication with physician, 5 items related to confidence on managing disease in general, 3 items related to confidence on doing chores, 2 items related to confidence on social and recreational activity, 1 item related to managing shortness of breathing The scoring system for total selfefficacy was less than 165 mean low self-efficacy, score from 165 to 215 mean mild self-efficacy, score from 216 to 281 mean moderate self-efficacy and score from 282 to 330 mean high self-efficacy.

\subsubsection{Reliability}

All tools used in this study were tested for its reliability using test retest reliability and all tools proved to be strongly reliable. (For tool two at. 91 and for tool three at. 83).

\subsubsection{Validity of the Tools}

All the tools for data collection were tested for its content validity by a panel of experts in community and psychiatric health nursing specialty to ascertain to its relevance and completeness and required modification was carried out accordingly.

\subsection{Procedure}

1-Preparatory phase: Review of relevant literature and different studies related to the topic of research was done to get a clear feature of all aspect of research topic and to design the data collection tools. Approval: An official permission was obtained from the Dean of the Liver Institute at Shebin El kom District, Menoufia Governorate to carry out to the study after the explanation of the aim of the study. Ethical consideration: Protection of human rights was emphasized to the patients that the participation in the study was voluntary. Anonymity and confidentiality of the responses were respected. The patients had the full right to refuse participating in the study or withdrawal at any time. Pilot study: Before starting data collection a pilot study were carried out on (5) patients, to assess the clarity, applicability and time needed to fill the tools. The necessary modifications were done as revealed from the pilot study. The sample of the pilot study was excluded from the total sample of the study. Data collection: The data were collected from the outpatient clinic in Liver Institute at Shebin El kom District, Menoufia Governorate using the above mentioned tools for data collection. The data were collected through three months, the time of study started from June to august 2015. The entire subjects who meet the inclusion criteria were included in the research, the subjects were divided into 8 groups ranged from 6 to 7 patients each group attends 8 sessions two sessions per week every session takes one hour. Implementation of the study passed into three phases (pre assessment phase, implementation phase and evaluation phase).

\subsubsection{Pre Assessment Phase}

A comfortable, private place was chosen for the interview. Orientation was done. Subject were interviewed individually at an outpatient clinic where pre assessment was done using tools for data collection.

\subsubsection{Implementation Phase}

The study hypnotized that application of the nursing intervention program will improve patients' emotional distress (anxiety and depression), self-efficacy and liver enzymes among Hepatitis C Virus patients undergoing antiviral treatment therapy. This intervention program was developed and given through the session. Each session has a specific objective. This was achieved through several teaching methods as brain storming, lecture, discussion and handout, Use illustrated media e.g. video, pictures and lab top.

- The objectives of the content of the nursing intervention program sessions was as follows:

- Define hepatitis C virus (HCV).

- Identify causes, precipitating factors of hepatitis $\mathrm{C}$ virus (HCV).

- Explain the general signs and symptoms of hepatitis $\mathrm{C}$ virus $(\mathrm{HCV})$

- List the different treatment regimens for patient having hepatitis $\mathrm{C}$ virus (HCV).

- Understand the mode of action and side effect of antiviral treatment therapy.

- Design plan of care for the patient.

- Set measure to protect the patient from the side effect of antiviral treatment therapy including sovadi and complication of illness.

- Identify diet regimen during taking treatment

- Use effective strategies to reduce feelings of emotional distress.

- Use stress management techniques to cope with physiological and psychological side effect of antiviral treatment therapy.

- Understand how to apply progressive muscle relaxation.

- Understand how to apply deep breathing exercises.

- Understand how to apply meditation.

A short description of the stress management techniques employed in the study are discussed below.

\section{(i) Progressive Muscle Relaxation (PMR) [25]}

"Is a technique for reducing stress and anxiety by alternately tensing and relaxing the muscles. It was developed by American physician Edmund Jacobson in the early 1920s. Jacobson argued that since muscle tension accompanies anxiety, one can reduce anxiety by learning how to relax the muscular tension. PMR entails a physical and mental component".

\section{(ii) Deep Breathing Exercises}

"Patients are taught by the researcher, manual or audio how to inhale and exhale deeper and slower. They need to practice several times a day, or as needed, for a few minutes to see immediate benefits". Method/Path physiology: -" (1) Sit comfortably with your back straight. Put one hand on your chest and the other on your stomach. (2) Breathe in through your nose. The hand on your stomach should rise. 
The hand on your chest should move very little. (3) Exhale through your mouth, pushing out as much air as you can while contracting your abdominal muscles. The hand on your stomach should move in as you exhale, but your other hand should move very little. (4) Continue to breathe in through your nose and out through your mouth. Try to inhale enough so that your lower abdomen rises and falls. Count slowly as you exhale".

\section{(iii) Meditation}

"Clients were given training on Meditation which involves assuming a comfortable position, closing the eyes, casting off all other thoughts and concentrating on a single word, sound, or a phrase that has positive meaning to the individual. It can be practiced $20 \mathrm{~m}$. once or twice daily".

The sessions for intervention were:

Session 1: This session concerned with open discussion for identification, integration of the group, clarification of the aim and time table allowed for intervention.

Session 2: This session was concerned with knowledge about definitions of hepatitis $\mathrm{C}$ virus (HCV), causes, precipitating factors of hepatitis $\mathrm{C}$ virus $(\mathrm{HCV})$ and method of protection from infection.

Session 3: This session focused on knowledge about clinical picture of hepatitis $\mathrm{C}$ virus, the role of nutrition and exercises on immune system.

Session 4: This session was concerned with knowledge about anti viral treatment therapy including Sovaldi medication (mode of action, side effect and importance of compliance on drug).

Session 5: This session concerned with the psychosocial impact of the illness and antiviral treatment therapy on patients' emotion and behavior.

Session 6 and 7: This session focused on stress management strategies to reduce emotional distress and improve coping with the illness and medication side effect.

Session 8: This session focused on the importance of emotional expressivity and assertiveness on emotional distress.

\subsubsection{Post Assessment Phase}

The researchers encourage participants to ask questions about the information and practices given in the previous session. The intervention evaluation was done using pre assessment tools of data collection.

\subsection{Statistical Analysis}

The results were statistically analyzed by statistical product of services solution SPSS version 20. Graphics were done using Excel program. Three types of statistics were done:
a) Descriptive: e.g., percentage (\%), mean and standard deviation SD
b) Analytical: - A Chi-Squared $\left(\chi^{2}\right)$ : It is used to compare between two or more qualitative variable.
c) Paired( t test) to compare between two mean

d) Parson correlation coefficient ( $\mathrm{r}$ test) were used to test the association between variable

- P value:

- Significant difference if $\mathrm{P}<0.05$

- Non-significant difference if $\mathrm{P}>0.05$.

- Highly significant difference if $\mathrm{P}<0.001$.

\subsection{Limitation of the Study}

No limitation founded.

\section{Results}

Table 1. Percentage distribution of Socio demographic characteristics of the studied.

\begin{tabular}{|c|c|c|}
\hline Socio-demographic Characteristics & Participants $(\mathrm{N}=\mathbf{5 0})$ & \\
\hline \multicolumn{3}{|l|}{ Age (years):- } \\
\hline $18-40$ & 25 & 50 \\
\hline $41-53$ & 9 & 18 \\
\hline$\geq 54$ & 16 & 32 \\
\hline Mean \pm SD & $39.5800 \pm 16.57893$ & \\
\hline \multicolumn{3}{|l|}{ Family Income:- } \\
\hline -Enough & 10 & 20 \\
\hline -Not enough & 40 & 80 \\
\hline Mean \pm SD & $1.8000 \pm .40406$ & \\
\hline \multicolumn{3}{|l|}{ Marital status:- } \\
\hline -Married & 40 & 80 \\
\hline -Widow & 10 & 20 \\
\hline \multicolumn{3}{|l|}{ Educational level:- } \\
\hline - Illiteracy & 5 & 20 \\
\hline -High education & 45 & 80 \\
\hline \multicolumn{3}{|l|}{ Job:- } \\
\hline -don't work & 10 & 20 \\
\hline -Employee & 35 & 70 \\
\hline -special work & 5 & 10 \\
\hline \multicolumn{3}{|l|}{ Educational level:- } \\
\hline - Illiteracy & 5 & 20 \\
\hline -High education & 45 & 80 \\
\hline \multicolumn{3}{|l|}{ Job:- } \\
\hline -don't work & 10 & 20 \\
\hline -Employee & 35 & 70 \\
\hline -special work & 5 & 10 \\
\hline
\end{tabular}

Table 1 reveals that the mean age of studied sample is (39.5800 \pm 16.57893$)$ years, in addition to the mean family income about (1.8000土.40406). 
Table 2. Percentage distribution of patients' complain pre | post program among the studied sample.

\begin{tabular}{|c|c|c|c|c|c|c|}
\hline \multirow{2}{*}{ Patients' complains } & \multicolumn{2}{|l|}{ Pre } & \multicolumn{2}{|c|}{ Post } & \multirow{2}{*}{$\chi^{2}$} & \multirow{2}{*}{$P$ value } \\
\hline & No. & $\%$ & No. & $\%$ & & \\
\hline drowsiness & 0 & 0 & 5 & 10 & \multirow{6}{*}{22.000} & \multirow{6}{*}{.001} \\
\hline Weakness and fatigue & 30 & 60 & 40 & 80 & & \\
\hline loss of appetite & 10 & 40 & 5 & 10 & & \\
\hline loss of weight & 0 & 0 & 0 & 0 & & \\
\hline Diarrhea & 5 & 10 & 0 & 0 & & \\
\hline Constipation & 5 & 10 & 0 & 0 & & \\
\hline
\end{tabular}

$\mathrm{P}=$ test of significance between pre and post program. (Chi test)

Table 2 shows that there is a reduction of the patients complain except weakness and fatigue (the post program than preprogram) with statistical significance difference at .001 .

Table 3. Percentage distribution of patient's knowledge about antiviral treatment therapy pre I post program among the studied sample.

\begin{tabular}{|c|c|c|c|c|c|c|}
\hline \multirow{2}{*}{ Knowledge about antiviral treatment therapy } & \multicolumn{2}{|l|}{ Pre } & \multicolumn{2}{|c|}{ Post } & \multirow{2}{*}{$\chi^{2}$} & \multirow{2}{*}{ P value } \\
\hline & No. & $\%$ & No. & $\%$ & & \\
\hline \multicolumn{7}{|l|}{ 1-Information about side effects of medication:- } \\
\hline Yes - & 0 & 0 & 80 & 45 & 1 & $.000 * * *$ \\
\hline - No & 100 & 50 & 20 & 5 & & \\
\hline \multicolumn{7}{|l|}{ 2-Perception about effectiveness of medication:- } \\
\hline - Effective & 20 & 10 & 80 & 40 & 0.162 & 3.64 \\
\hline - Not effective & 20 & 10 & 10 & 5 & & \\
\hline - Not sure & 60 & 30 & 10 & 5 & & \\
\hline \multicolumn{7}{|l|}{ 3- Diet regimen during taking medication? } \\
\hline -Yes & 0 & 0 & 90 & 45 & 1 & $.000 * * *$ \\
\hline - No & 100 & 50 & 10 & 5 & & \\
\hline
\end{tabular}

$\mathrm{P}=$ test of significance between pre and post program. (Chi test)

Table 3 shows that, there is a highly statistically significant improvement of patients' knowledge about antiviral treatment therapy (Sovaldi) medication as its side effects, and information's about diet regimen during taking it (post program than preprogram) at .000 while insignificant improvement in patients' perception about effectiveness of anti viral treatment therapy.

Table 4. Percentage distribution of patient's knowledge about Hepatitis C virus pre I post program among the studied sample.

\begin{tabular}{|c|c|c|c|c|c|c|}
\hline \multirow{2}{*}{ Patients knowledge about (Hepatitis $\mathrm{C}$ virus) } & \multicolumn{2}{|l|}{ Pre } & \multicolumn{2}{|l|}{ Post } & \multirow{2}{*}{$\chi^{2}$} & \multirow{2}{*}{ P value } \\
\hline & No. & $\%$ & No. & $\%$ & & \\
\hline 1-Causes of hepatitis $\mathrm{C}$ virus:- & & & & & 1 & \\
\hline - Yes & 40 & 20 & 90 & 45 & & \\
\hline - No & 60 & 30 & 10 & 5 & 0.048 & $.000^{* * *}$ \\
\hline \multicolumn{7}{|l|}{ 2- Methods of protection:- } \\
\hline Yes - & 14 & 7 & 90 & 45 & & $.000^{* * *}$ \\
\hline - No & 86 & 43 & 10 & 5 & & \\
\hline
\end{tabular}

$\mathrm{P}=$ test of significance between pre and post program. (chi test)

Table 4 shows that there is a highly statistically significant improvement of patients' knowledge about Hepatitis $\mathrm{C}$ virus related causes and the methods of protection from Hepatitis $C$ virus (the post program than preprogram) at .000 . 


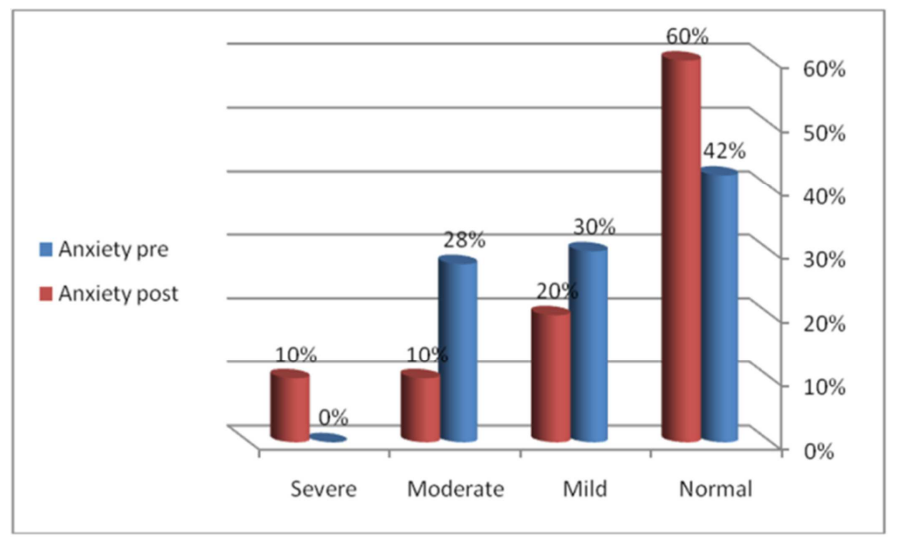

$\mathrm{P}=$ test of significance between pre and post program. (Chi test) at $0.024 * *$

Figure 1. Percentage distribution of the emotional distress (anxiety) pre | post program among the studied sample.

Figure 1 shows that, there is a highly statistically significant improvement of emotional distress as regarding to (anxiety) at 0.024 post program than preprogram in which the percentage of patients who have no anxiety preprogram (42\%) increase to $60 \%$ and also the patient who have mild anxiety reduced from $30 \%$ to $20 \%$ and moderate anxiety reduced from $28 \%$ to $10 \%$ post program than before the program.

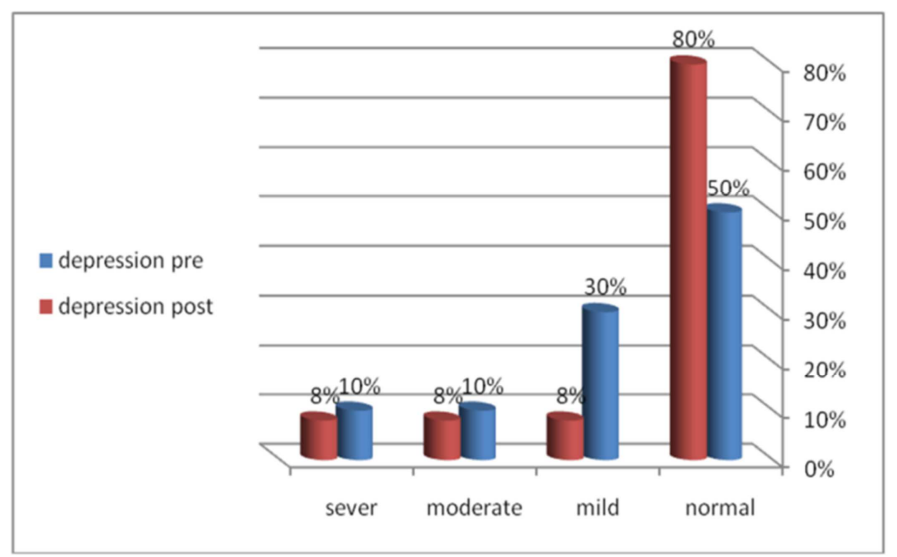

$\mathrm{P}=$ test of significance between pre and post program. (Chi test) at $0.000 * * *$

Figure 2. Percentage distribution of the emotional distress (depression) pre I post program among the studied sample.

Figure 2 shows that, there is a highly statistically significant improvement of emotional distress as regarding to (depression) at 0.000 post program than preprogram in which the percentage of patients who have no depression preprogram (50\%) increase to $80 \%$ and also the patient who have mild depression reduced from $30 \%$ to $8 \%$ and both moderate and severe depression reduced from $10 \%$ to $8 \%$ post program than before the program.

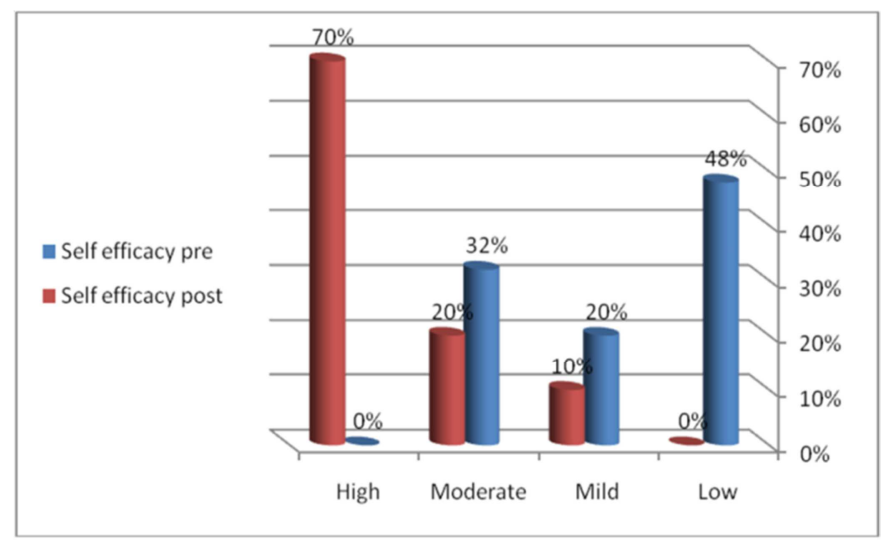

$\mathrm{P}=$ test of significance between pre and post program. (Chi test) at $.043^{* *}$

Figure 3. Percentage distribution of the self-efficacy levels pre | post program among the studied sample. 
Figure 3 reveals that, there is statistically significant improvement of patients' self-efficacy post program than preprogram at .043, where the percentage of higher self-efficacy increase from $0 \%$ preprogram to $70 \%$ post program.

Table 5. Mean Differences of liver enzyme prel post program among the studied sample.

\begin{tabular}{|c|c|c|c|c|}
\hline \multirow{3}{*}{ liver enzyme } & \multicolumn{2}{|l|}{ Study group N (50) } & \multirow{3}{*}{ t-test } & \multirow{3}{*}{ P value } \\
\hline & Pre program & Post program & & \\
\hline & Mean \pm SD & Mean \pm SD & & \\
\hline \multicolumn{5}{|l|}{ 1-ALT enzyme } \\
\hline -Total mean score of (ALT) & $42.2400 \pm 2.2907$ & $39.7600 \pm .44309$ & -2.167 & .035 \\
\hline \multicolumn{5}{|l|}{ 2-AST enzyme } \\
\hline -Total mean score of (AST) & $67.1000 \pm 14.5717$ & $40.8800 \pm 1.9020$ & 6.807 & .000 \\
\hline
\end{tabular}

$\mathrm{P}=$ test of significance between pre and post program. (Paired $\mathrm{t}$ test)

Table 5 reveals that there is a significant reduction of liver enzyme post program than preprogram where the total mean score of (AST) preprogram are $(67.1000 \pm 14.5717$ decrease to $40.8800 \pm 1.9020)$ post program at statistical significance .000 while, the total mean score of (ALT) preprogram is $(42.2400 \pm 2.2907$ decreased to $39.7600 \pm .44309)$ post program at statistical significance .035 .

Table 6. Correlation between means score of liver enzyme and total mean score of anxiety pre $\mid$ post program among the studied sample.

\begin{tabular}{|c|c|c|c|c|}
\hline \multirow{3}{*}{ Liver enzyme } & \multicolumn{4}{|c|}{ Pearson correlation Total score of anxiety } \\
\hline & \multicolumn{2}{|c|}{ Pre program } & \multicolumn{2}{|c|}{ Post program } \\
\hline & $\mathbf{r}$ & P-value & $\mathbf{r}$ & P-value \\
\hline 1-ALT enzyme & 0.157 & .276 & $.706^{* *}$ & .000 \\
\hline 2-AST enzyme & 0.193 & .180 & $.876^{* *}$ & .000 \\
\hline
\end{tabular}

** Correlation is significant at the 0.01 level (2-tailed).

Table 6 shows that there is a positive insignificant correlation between mean scores of liver enzymes and total mean scores of anxiety preprogram, while there is a highly positive significant correlation post program (i.e. when liver enzymes decrease, the anxiety decrease and vice verse).

Table 7. Correlation between means score of liver enzyme and total mean score of depression prel post program among the studied sample.

\begin{tabular}{|c|c|c|c|c|}
\hline \multirow{3}{*}{ Liver enzyme } & \multicolumn{4}{|c|}{ Pearson correlation Total score of depression } \\
\hline & \multicolumn{2}{|c|}{ Pre program } & \multicolumn{2}{|c|}{ Post program } \\
\hline & $\mathbf{r}$ & P-value & $\mathbf{r}$ & P-value \\
\hline 1-ALT enzyme & 0.142 & .324 & $.354^{*}$ & .012 \\
\hline 2-AST enzyme & 0.198 & .168 & $.324 *$ & .022 \\
\hline
\end{tabular}

** Correlation is significant at the 0.01 level (2-tailed).

Table 7 shows that there is a positive insignificant correlation between mean score of liver enzymes and mean total score of depression, while post program there is a high positive significant correlation (i.e. when liver enzymes, increase the depression increase and vice verse) which mean that the program is very effective.

Table 8. Correlation between means score of liver enzyme and total mean score of self-efficacy prel post program among the studied sample.

\begin{tabular}{lllll}
\hline \multirow{2}{*}{ Liver enzyme } & \multicolumn{2}{l}{ Pearson correlation Total score of self-efficacy } \\
\cline { 2 - 4 } & \multicolumn{2}{l}{ Pre program } & Post program \\
\cline { 2 - 4 } & $\mathbf{r}$ & P-value & r & P-value \\
\hline 1-ALT enzyme & 0.006 & .969 & .167 & .247 \\
2-AST enzyme & $-0.323 *$ & .022 & $.334^{*}$ & .018 \\
\hline
\end{tabular}

** Correlation is significant at the 0.01 level (2-tailed). 
Table 8 shows that there is an insignificant correlation between mean score of ALT and total mean score of self-efficacy prelpost program and there is a negative significant correlation between mean scores of AST and mean scores of total selfefficacy preprogram (i.e. when AST decrease, self-efficacy increase) while there is a positive significant correlation between mean scores of AST and mean scores of total self-efficacy post program (i.e. when AST increase, self-efficacy increase) which mean that the program is very effective in increasing, self-efficacy in spite of increase AST.

Table 9. Correlation between total mean scores of emotional distress (anxiety \& depression) and total score of self-efficacy pre lpost program among the studied sample.

\begin{tabular}{|c|c|c|c|c|}
\hline \multirow{3}{*}{ Total mean scores of anxiety, depression } & \multicolumn{4}{|c|}{ Pearson correlation Total score of self-efficacy } \\
\hline & \multicolumn{2}{|c|}{ Pre program } & \multicolumn{2}{|c|}{ Post program } \\
\hline & $\mathbf{r}$ & P-value & $\mathbf{r}$ & P-value \\
\hline 1-Anxiety & 0.122 & .399 & -.202 & .160 \\
\hline 2-Depression & $-0.589 * *$ & .000 & .190 & .187 \\
\hline
\end{tabular}

** Correlation is significant at the 0.01 level (2-tailed).

Table 9 shows that there is an insignificant correlation between total mean score of anxiety and total mean score of self-efficacy prelpost program, there is a negative significant correlation between total mean score of depression and total mean score of self-efficacy preprogram i.e.(when depression decrease, the self-efficacy increase), while there is a positive significant correlation between total mean score of depression and total mean score of self-efficacy post program (i.e. when depression increases, the self-efficacy increase) which mean the program is very effective in improving selfefficacy in spite of depression.

\section{Discussion}

Patients with HCV are faced with a number of challenges, including adjustment to a chronic medical illness, management of symptoms and treatment side effects, and making and maintaining lifestyle changes. Given these issues, mental health clinicians have the opportunity to make a significant contribution to patient care [26]. Drug regimens for treating $\mathrm{HCV}$ infection are not easy for patients to complete. Most patients experience side effects, and non adherence is common. However, adherence to the prescribed regimen is crucial to the success of the treatment plan, so the treatment team must take an aggressive approach to helping patients follow their treatment regimen. While the treatment experience varied between patients, several common themes consistently emerged, including the severity and breadth of medication side effects, the desire for increased support, and the difficulties balancing work and treatment. Because of new developments in antiviral therapy for hepatitis, the hematology nurses are critical to their care and management. These dedicated nurses go the extra mile in providing support, education, counseling and referrals that provide the greatest opportunity for staying on treatment and receiving care [27]. So this study was done to evaluate the effectiveness of nursing intervention program on patients' emotional distress, self-efficacy and liver enzymes. The current study represented that the mean age of studied sample was $(39.5800 \pm 16.57893)$ years, this finding supported with the result of [28], who assess the effect of nursing management protocol on selected side effects of Interferon and Ribavirin among hepatitis $\mathrm{C}$ patients. They revealed that the mean age of their study sample was $41.06 \pm 9.31$ years. Also, on the same line, the finding of study conducted by [18], who reported that "Hepatitis C virus is an infectious disease affecting primarily the liver, caused by the hepatitis $\mathrm{C}$ virus, the infection is often asymptomatic, but chronic infection can lead to scaring of the liver and ultimately to cirrhosis, which is generally apparent through any age".

The reference [29] stated that "adverse reactions can occur with any drug even over- the counter medications. The most frequently reported adverse events across all treatment arms were fatigue, headache, insomnia and nausea. Flu-like illness and fever were more common with the interferon-containing regimen". This was in line with the finding of the current study which showed that most studied sample suffered from weakness and fatigue, loss of appetite, diarrhea and constipation during antiviral treatment therapy pre intervention program; while after the intervention program, the Findings revealed that the intervention program was effective in reducing patients complain as drowsiness, loss of appetite, loss of weight, diarrhea and constipation during antiviral treatment therapy with statistically significant difference between pre and post nursing intervention ( $p$ $=.001$ ); this could be due to the effect of intervention program in increasing patients ability to deal with and managing medication side effect. Consistent with the present finding reference [30], they showed that; "the clients' dietary behavior is improved from pre to post nursing intervention $(2.2 \pm 1.1$ to $7.5 \pm 0.3)$ and concluded that changes in food intake are very important for clients with chronic hepatitis $\mathrm{C}$ to improve some symptoms such as nausea, fatigue, depression and appetite".

The reference [31], mentioned that; "fatigue is a common side effect of IFN and is reported in $70 \%$ to $100 \%$ of patients; it generally increases in intensity as therapy continues and can be very debilitating". The finding of the present study revealed that there was no significant difference regarding the patient's complain from weakness and fatigue between pre and post intervention program; this could be due to patients' believe that fatigue was a sign of disease 
progression which as a result contribute to patients' beliefs that weakness and fatigue were uncontrollable and this supported by [32], who stated that; "the cognitive-behavioral theory posits that patients' beliefs about the illness and fatigue and their coping behaviors, rather than objective disease measures, determine the experience and the consequences of fatigue. When patients are aware of having a chronic illness, they interpret sensations (including fatigue) in the context of their knowledge and beliefs about the illness. These interpretations shape the behaviors that patients adopt to cope with fatigue. The coping behaviors may, in some cases, be non-adaptive whereby they perpetuate rather than alleviate fatigue". Also The insignificant effect of the intervention program on the patient's complain from weakness and fatigue between pre and post intervention program might be due to abnormal circulating levels of thyroxin or TSH for the studied patient this was supported by [33], who mentioned that; "thyroid dysfunction has been reported in $2-13 \%$ of $\mathrm{HCV}$-infected patients; however, this incidence increases to $15-40 \%$ with the use of interferon".

The results of the present study showed that, there was a highly statistically significant improvement of patients' knowledge about Anti viral treatment therapy as it's action, dose, route, frequency, side effects and how to deal with it, information's about diet regimen during taking it (post program than preprogram) at .000; This might be attributed to the program sessions that were provided to cover all aspects of anti viral treatment therapy which eventually increase patients knowledge; consistent with this result [28], who showed that; "there was significant improvement of sample knowledge in approximately every aspects of knowledge given to them than pre intervention". While the current result revealed that there was insignificant improvement in patients' perception about effectiveness of anti viral treatment therapy (sovaldi) after intervention program; this could be due to that patients were far from realizing ideal cure rates and that the potential side effects of the treatment were significant. Also; this could be due to concerns that treatment will worsen preexisting psychological conditions or that such preexisting co morbidities will interfere with treatment adherence.

The reference [34], stated that; "nurses play an important role in clients' education. They explain hepatitis to infected clients, tell them how the disease usually progresses and advise them on when to contact a doctor. Nurse should have acquired adequate information and insights to care effectively and safely for clients with viral hepatitis. The primary care nurse may undertake tasks such as specific diagnosis and initial assessment of the severity of disease, counseling the clients about the current understanding of the disease process and potential complications, as well as general issues of diet, mental health, and recommendations about health-promoting lifestyle". On the same line; the result of the current study which showed that there was a highly statistically significant improvement of patients' knowledge about hepatitis $\mathrm{C}$ virus related causes and the methods of protection from Hepatitis $\mathrm{C}$ virus (post program than preprogram) at .000 . This result was supported by the result of [28], who found that; "there was significant improvement of their sample knowledge in approximately every aspects of knowledge given to them after their intervention". These results were consistent with [35] who showed a statistical significant difference between before and after conduction the nursing management protocol that indicates an improvement of patients total mean score of knowledge after intervention.

The reference [36] mentioned that; "sever anxiety is a very common side effects in clinical trial in $30 \%$ or more of patients and if patients are aware that medications predispose them to anxiety and learn how to deal with it, they can control anxiety more effectively". These were consistent with the results of the present study which revealed that there was a highly statistically significant improvement of emotional distress as regarding to (anxiety) at 0.024 post program than preprogram in which the percentage of patients who have no anxiety preprogram (42\%) increase to $60 \%$ and also the patient who have mild anxiety reduced from $30 \%$ to $20 \%$ and moderate anxiety reduced from $28 \%$ to $10 \%$ post program than before the program; this could be as a result of stress management training session which taught them to control anxiety, to express negative feeling, and to cope more effectively with stress.

The result of the current study revealed that, there is a highly statistically significant improvement of emotional distress as regarding to (depression) at 0.000 post program than preprogram in which the percentage of patients who have no depression preprogram (50\%) increase to $80 \%$ and also the patient who have mild depression reduced from $30 \%$ to $8 \%$ and both moderate and severe depression reduced from $10 \%$ to $8 \%$ post program than before program; this could be as a result of psych educational program which help them to acquire the skills to learn how to relax, and how to manage somatic side effects.; furthermore, the group discussion in intervention programs session help reduce these patients' feelings that they are alone and their situation is unique, in turn reducing their frustration, talk of feelings of depression and anxiety are more easily tolerated from group members, and in fact seem to be quite common among them. Agreement with the present study, reference [37] they stated that; "Psychosocial interventions could be used as an adjunct or alternative to antidepressants to address the sequel of antiviral treatment for HCV". Moreover, [38] concluded that; "As compared with usual care, an intervention involving nurses who provided guideline-based, patient-centered management of depression and chronic disease significantly improved control of medical disease and depression".

There is evidence that many factors determine medication adherence, including adherence self-efficacy (confidence in one's ability to adhere) and relations with health care providers. [39], concluded that; "Positive provider interactions may foster greater adherence self-efficacy, which is associated with better adherence to medications". The current study revealed that, there is statistically significant improvement of patients' self-efficacy post program than 
preprogram at .043 , where the percentage of higher selfefficacy increase from $0 \%$ preprogram to $70 \%$ post program; this could be due to reduction of the emotional distress (anxiety and depression), reduction of physical symptoms and due to improvement on the liver enzymes or due to increasing their awareness' about the temporary side effect of the drugs and patients prognosis. The present result was agreement with [40] who showed that A recent Cochrane review provided evidence of the effectiveness of patient support and education interventions, reporting that;" interventions targeting practical medication management skills, administered to individuals (vs groups), and delivered over at least 12 weeks were associated with improved adherence outcomes". Moreover, this result supported by [41], they performed a prospective study to determine the effects of systematic consultation by a nurse on patient adherence and the efficacy of therapy, they concluded that; "therapeutic education by a specialized nurse increases the response of patients with hepatitis $\mathrm{C}$ to therapy, particularly in difficult-to-treat patients".

The present study revealed that there was significant reduction of liver enzyme post program than preprogram where the total mean score of (AST) preprogram are $(67.1000 \pm 14.5717$ decrease to $40.8800 \pm 1.9020)$ post program at statistical significance .000 while, the total mean score of (ALT) preprogram was (42. 2400 \pm 2.2907 decreased to $39.7600 \pm .44309)$ post program at statistical significance .035 . This could be due to the effect of the use of stress management and assertiveness by the patients during the program. Consistent with this result [28], their results revealed that the mean Asparate Aminotransferase and Alanine Aminotransferase were increased before applying the nursing intervention while with a significant improvement after applying the nursing intervention. Moreover, this was in agreement with [42] who stated that; "nursing intervention for patients with liver diseases has a number of positive effects on physical responses including laboratory findings". Also, this was supported by [43] who showed that mean Asperate and Alanine Aminotransferase were decreased after patient education and this alteration was significant. Also supported this finding [30] the findings of their study revealed that there are highly statistically significant between total blood investigation of clients at pre intervention program and post intervention program which one quarter of clients was normal changed to three quarter of clients after nursing intervention. Consistently, [44] who studied "Effects of lifestyle changes including specific dietary intervention and physical activity in the management of patients with chronic hepatitis C". They reported that; "intervention program had significant improvements on liver function testes".

The present study showed that there is a highly positive significant correlation between mean scores of liver enzymes and total mean scores of anxiety and depression post program (i.e. when liver enzymes decrease the anxiety and depression decrease and vice verse); this result was supported by [45], who stated that; "Liver function enzymes especially AST
(SGOT) and ALT (SGPT) are reasonably sensitive indicators of liver damage or injury from different types of diseases or conditions", so they are associated with distressed psychological status in hepatitis c patients. Also, the current result was consistent with [46] who found that alanine aminotransferase (ALT) and aspertate aminotransferase (AST) values are strongly correlated with high stress levels in patients with HCV liver cirrhosis. Moreover, the current finding was in parallel with [47], who find that the psychological distress in cirrhosis such as depression and anxiety were correlated specifically to increased levels of AST, as AST is an important mediator of the inflammatory processes, and increasing evidence has suggested that pathophysiology of depression is closely related to the proinflammatory cytokines, and the findings of the association between AST and depression may be related to the chronic inflammation in cirrhosis.

The reference [48], their main results distinguished that there is a significant and negative relationship between total self-efficacy, physical self-efficacy and academic selfefficacy and depression and they concluded that the various aspects of mental health is influenced by the sense of self efficacy appraisal. So, low self efficacy usually increases some problems such as emotional and social problems which involves in mental health. This result contradicted to the result of the current study, which revealed that there is a positive significant correlation between total mean score of depression and total mean score of self-efficacy post program (i.e. when depression increases, the self-efficacy increase), which mean that the program is very effective in improving self-efficacy in spite of the present of depression. Also the present study revealed that there is a positive significant correlation between mean score of AST and mean score of total self-efficacy post program (i.e. when AST increase, selfefficacy increase), which mean that the program is very effective in increasing, self-efficacy in spite of increase AST.

\section{Conclusion}

Nursing intervention program is the key element for management of patients' emotional distress, self-efficacy and reduction of liver enzymes of hepatitis C Virus patients undergoing antiviral treatment therapy.

\section{Recommendation}

Based on the results of this study we recommend that: psych educational program should be given for all patients with hepatitis $C$ virus undergoing antiviral treatment therapy to:-

- Improve their knowledge about the drug and promote adherence by counseling patients on the recognition and management of treatment related adverse effect.

- Encourage them to discuss their problem with health care team and participate in self-help program to decrease emotional distress and increase self-efficacy. 


\section{References}

[1] European Association for Study of Liver. (2014). EASL Clinical Practice Guidelines: management of hepatitis C virus infection. Journal of Hepatology, 60 (2), 392.

[2] Dhawan, V. K., and Anand, B. S.: Hepatitis C, 2014.

[3] Ferenci P. Peginterferon and ribavirin in HCV: Improvement of sustained viral response. Best Pract Res Clin Gastroenterol. 2008; 22: 1109-1122. [PubMed]

[4] Iliades, C. (2014): 8 Ways to Relieve Depression from Hep C, www.everydayhealth.com/.../steps-to-overcoming-depre.

[5] Younossi, Z., Kallman, J., \& Kincaid, J. (2007). The effects of $\mathrm{HCV}$ infection and management on health related quality of life. Hepatology, 45 (3), 806-816.

[6] Evon, D. M., Golin, C. E., Fried, M. W., \& Keefe, F. J. (2013). Chronic hepatitis $\mathrm{C}$ and antiviral treatment regimens: where can psychology contribute? Journal of -consulting and clinical psychology, 81 (2), 361.

[7] Foster GR. (2009): Quality of life considerations for patients with chronic hepatitis C. Journal of Viral Hepatitis.; 16: 605-11.

[8] American Association, 2014. American Association for the Study of Liver Disease, "AASLD Statement on HCV Guidance,"

http://www.aasld.org/practiceguidelines/Pages/AASLDStatem entonHCVGuidance.aspx (accessed August 16, 2014).

[9] Lucinda K. Porter, RN \& Alan Franciscus, Editor-in-Chief, HCSP Publications "Gilead Gets U.S. Approval to Sell New Hepatitis C Drug," The Wall Street Journal, October 10, 2015, http://online.wsj.com/articles/gilead-gets-u-s-approval-to-sellnew-hepatitis-c-drug-1412963083 (accessed October 12, 2015). Approval to Sell New Hepatitis C Drug," The Wall Street Journal, October 10, 2014, http://online.wsj.com/articles/gileadgets-u-s-approval-to-sell-new-hepatitis-c-drug-1412963083 (accessed October 12, 2015).

[10] Ez-Quevedo C, Masnou H, Planas R, Castellvi P, Gimenez D, Morillas RM, et al. Prophylactic treatment with escitalopram of pegylated interferon alfa-2a-induced depression in hepatitis C: a 12-week, randomized, double-blind, placebo-controlled trial. J. Clin. Psychiatry. 2011; 72 (4): 522-528. [PubMed]

[11] Kraus MR, Schafer A, Schottker K, Keicher C, Weissbrich B, Hofbauer I, et al. Therapy of interferon-induced depression in chronic hepatitis $\mathrm{C}$ with citalopram: a randomised, doubleblind, placebo-controlled study. Gut. 2008; 57 (4): 531-536. [PubMed]

[12] Gilead, A. (2013): Gilead's Sciences, Inc. Sovaldi is a registered trademark of Gilead's Sciences, Inc. available at www.gilead.com

[13] Jake Liang and Marc G. Ghany, "Editorial: Therapy of Hepatitis C-Back to the Future," New England Journal of Medicine (May 2014): http://globalhealth.med.ucla.edu/programs/therapyofhepc.pdf.

[14] Avik Roy, "The Sovaldi Tax: Gilead Can't Justify the Price It's Asking for Hepatitis C Therapy," Forbes, June 17, 2014, http://www.forbes.com/sites/theapothecary/2014/06/17/thesovaldi-tax-gilead-cant-justify-the-price-its-asking-americansto-pay (accessed December 12, 2014).
[15] Jonathan D. Rockoff, "Gilead Gets U.S. Approval to Sell New Hepatitis C Drug," The Wall Street Journal, October 10, 2015, http://online.wsj.com/articles/gilead-gets-u-s-approval-to-sellnew-hepatitis-c-drug-1412963083 (accessed October 12, 2015).

[16] Gilead, 2015 "Gilead Gets U.S. Approval to Sell New Hepatitis C Drug," The Wall Street Journal, October 10, 2015, http://online.wsj.com/articles/gilead-gets-u-s-approval-to-sellnew- hepatitis-c-drug-1412963083 (accessed October 12, 2015).

[17] Tawfik EH. (2011): Impact of an educational program on Health Related Quality of Life among virus hepatitis c patients. Alexandria University. High Institute of Public Health.

[18] Stephen Miller, "State Governments May Spend \$55 Billion on Hepatitis C Medications," Express Scripts, posted July 17, 2014, http://lab.express-scripts.com/insights/specialty medications/state-governments-may-spend-\$55-billion- onhepatitis-c-medications (accessed January 25, 2015).

[19] Waldman R., (2014) Gilead's HCV drug Sofosbuvir approved by the FDAbut accessible for how many? Doctors of the world; 6 (4); 27-4Retrived on 22 February.

[20] Sgorbini, M., O’Brien, L., \& Jackson, D. (2009). Living with hepatitis $\mathrm{C}$ and treatment: the personal experiences of patients. Journal of clinical nursing, 18 (16), 2282-2291.

[21] Hong, B. A., North, C. S., Pollio, D. E., Abbacchi, A., Debold, C., Adewuyi, S. A., \& Lisker-Melman, M. (2011). The use of psychoeducation for a patient with hepatitis $\mathrm{C}$ and psychiatric illness in preparation for antiviral therapy: a case report and discussion. Journal of clinical psychology in medical settings, 18 (1), 99-107.

[22] Zigmond, AS; Snaith, RP (1983): "The hospital anxiety and depression scale". Acta Psychiatrica Scandinavica 67 (6): 361-370. doi:10.1111/j.1600-0447.1983.tb09716.x. PMID 6880820 .

[23] Lorig K, Stewart A, Ritter P, González V, Laurent D, \& Lynch $\mathrm{J}$, Outcome Measures for Health Education and other Health Care Interventions. Thousand Oaks CA: Sage Publications, 1996, pp. 24-25, 41-45.

[24] Jacobson E. Progressive relaxation. Chicago: University of Chicago Press. 1938.

[25] Silberbogen, A. K., Ulloa, E. W., Janke, E. A., \& Mori, D. L. (2009). Psychosocial issues and mental health treatment recommendations for patients with hepatitis C. Psychosomatics, 50 (2), 114-122.

[26] Ford, J. A., \& Cheong-Lee, C. (2007). The role of the hepatology nurse in the difficult-to- treat hepatitis C population. Canadian Journal of Gastroenterology, 21 (6), 353.

[27] Mohsen, M. M., Fareed, M. E., El-Sheikh, A. A., \& Abbas, S. M. (2011). Effect of nursing management protocol on selected side effects of interferon and ribavirin among hepatitis $\mathrm{C}$ patients. Journal of American science, 7 (6), 54-63.

[28] Foster GR et al (2015). Sofosbuvir + peginterferon/ribavirin for 12 weeks vs sofosbuvir + ribavirin for 16 or 24 weeks in genotype $3 \mathrm{HCV}$ infected patients and treatment-experienced cirrhotic patients with genotype $2 \mathrm{HCV}$ : the BOSON study. EASL 50th International Liver Congress, Vienna, abstract L05, 2015. 
[29] El-Maksoud, M. M. A., El-Mohsen, A. S. A., Talhat, T., \& Abdalla, N. Nursing Intervention for Changing the Lifestyle of Chronic Hepatitis C. Volume 4, Issue 4 Ver. IV (Jul. - Aug. 2015), PP 75-83 www.iosrjournals.org

[30] Hauschild, A. Gogas, H. Tarhini, A. Middleton, M, R. Testori, A. Brigitte, D. Kirkwood, J, M. (2008): Practical Guidelines for theManagement of Interferon-a-2b Side Effects in Patients Receiving Adjuvant Treatment for Melanoma, onlinelibrary.wiley.com/doi/10.1002/cncr.23251/pdf.

[31] Goedendorp, M. M., Gielissen, M. F., Verhagen, C. A., Peters, M. E., \& Bleijenberg, G. (2008). Severe fatigue and related factors in cancer patients before the initiation of treatment. British Journal of Cancer, 99, 1408-1414.

[32] Mandac JC, Chaudhry S, Sherman KE, Tomer Y. The clinical and physiological spectrum of interferon-alpha induced thyroiditis: toward a new classification. Hepatology 2006; 43 (4): 661-672.

[33] Morgan, L. A.,: Nursing Responsibilities in Patients with Hepatitis C. 2012 http://www.ehow.com/list_6137912_nursing-responsibilitiespatients-hepatitis- c.html $\overline{\text { Hixzz} 2 F u g d 89 D K}$

[34] Fareed M. (2004). Dietary management in chronic renal failure patients and its effects on nutritional states, renal function tests and serum electrolytes. Unpublished Doctoral degree, Faculty of Nursing; Menoufyia University.

[35] National Hepatitis C Program. (2007). Interferon and Ribavirin treatment side effects. United States Development and Veterans Affairs. 1 (1): 1-12.

[36] Ramsey, S. E., Engler, P. A., Stein, M. D., Brown, R. A., Cioe, P., Kahler, C. W.,... \& Solomon, D. A. (2011). Effect of CBT on depressive symptoms in methadone maintenance patients undergoing treatment for hepatitis C. Journal of addiction research \& therapy, 2 (2), 2.

[37] Katon, W. J., Lin, E. H., Von Korff, M., Ciechanowski, P., Ludman, E. J., Young, B.,... \& McCulloch, D. (2010). Collaborative care for patients with depression and chronic illnesses. New England Journal of Medicine, 363 (27), 26112620 .

[38] Johnson, M. O., Chesney, M. A., Goldstein, R. B., Remien, R. H., Catz, S., Gore-Felton, C.,... \& Morin, S. F. (2006). Positive provider interactions, adherence self-efficacy, and adherence to antiretroviral medications among HIV-infected adults: A mediation model. AIDS Patient Care \& STDs, 20 (4), 258-268.
[39] Rueda, S., Park-Wyllie, L. Y., Bayoumi, A. M., Tynan, A. M., Antoniou, T. A., Rourke, S. B., \& Glazier, R. H. (2006). Patient support and education for promoting adherence to highly active antiretroviral therapy for HIV/AIDS. Cochrane Database Syst Rev, 3 (3).

[40] Larrey, D., Salse, A., Ribard, D., Boutet, O., Hyrailles-Blanc, V., Niang, B.,... \& Karlova, N. (2011). Education by a nurse increases response of patients with chronic hepatitis $\mathrm{C}$ to therapy with peginterferon- $\alpha 2 \mathrm{a}$ and ribavirin. Clinical Gastroenterology and Hepatology, 9 (9), 781-785.

[41] Heneedy W. (2009) Study of the effect of nursing intervention on physical responses and compliance among patients with liver cirrhosis at National Liver Institute and Menoufyia university hospital. Unpublished Doctoral Thesis, Faculty of Nursing; Menoufyia University.

[42] Alavian S, Kabir A, Hajarizadeh B, Nayebpour M, Dorodi T and Baralle F. (2006). Preliminary report of Interferon Alfa $2 b$ in combination with Ribivirin for 48 weeks for treatment of Iranian patients with chronic hepatitis C: A quasi-experimental study. Shiraz E-Medical Journal, 7 (1): 1-11.

[43] Rusu, E., Jinga, M., Enache, G., Rusu, F., and et al.: Effects of lifestyle changes including specific dietary intervention and physical activity in the management of patients with chronic hepatitis C - a randomized trial. Nutrition Journal; 2013, 12: 119. http://www.nutritionj.com/content/12/1/119

[44] Patrick, C, D. (2014): Liver blood tests, Available at www. medicinenet.com > home > liver blood tests index.

[45] Constantin, C, V. Teodor, C, S. Maria, L, S. Gabriel, A, I. Sima, F. (2009): Psychosocial stress and liver disease status, World J Gastroenterol, v, 15 (24), Available at www.ncbi.nlm.nih.gov > NCBI > Literature > PubMed Central (PMC).

[46] Yuan, F, K. Albert, C, Y. Jen, S, T. Zhou, Y. Ming, L, X. (2013): Physiologic and laboratory correlates of depression, anxiety, and poor sleep in liver cirrhosis, BMC Gastroenterol, $\mathrm{V}, 13$ (18), Available at www.ncbi.nlm.nih.gov > NCBI > Literature > PubMed Central (PMC).

[47] Tahmassian, K., \& Jalali Moghadam, N. (2011). Relationship between self-efficacy and symptoms of anxiety, depression, worry and social avoidance in a normal sample of students. Iranian journal of psychiatry and behavioral sciences, 5 (2), 91-98. 